\title{
Age-related methylation profiles of equine blood leukocytes in the RNASEL locus
}

\author{
T. Ząbek ${ }^{1}$ - E. Semik ${ }^{1}$ T. Szmatola ${ }^{1}$ - B. Oklejewicz ${ }^{2}$ A. Fornal ${ }^{1}$. \\ M. Bugno-Poniewierska ${ }^{1}$
}

Received: 5 November 2014 /Revised: 22 September 2015 / Accepted: 14 October 2015 / Published online: 9 November 2015

(C) The Author(s) 2015. This article is published with open access at Springerlink.com

\begin{abstract}
Methylation profiles across three $\mathrm{CpG}$ islands of the RNASEL gene were determined in blood leukocyte samples of Anglo-Arabian and Hucul horses. Bisulfite sequencing revealed hypomethylated state of the RNASEL promoter coinciding with methylated $\mathrm{CpG}$ island placed inside the gene. Several CpG sites were identified for which the methylation state was influenced by DNA polymorphism. Two of them showed monoallelic methylation. One of the $\mathrm{CpG}$ sites revealed functional polymorphism. A number of partially methylated $\mathrm{CpG}$ sites have been observed in the promoter area of $R N A S E L$, which were used for the comparison of breed- and age-related effects. Clone bisulfite sequencing of blood leukocyte samples collected at different ages from particular individuals of $\mathrm{AA}$ and $\mathrm{HC}$ breeds and, also, BSPCR sequencing of 50 samples of juvenile and old AA and $\mathrm{HC}$ horses revealed increased methylation in particular $\mathrm{CpG}$ sites during aging. The age-related heterogeneity of white blood cells was hypothesized as being one of the potential causes of observed variability of methylation profiles in the RNASEL promoter.
\end{abstract}

Keywords $R N A S E L \cdot$ Horses $\cdot$ DNA methylation . Leukocytes $\cdot$ Aging

Communicated by: Maciej Szydlowski

Electronic supplementary material The online version of this article (doi:10.1007/s13353-015-0323-4) contains supplementary material, which is available to authorized users.

\section{T. Ząbek}

tomasz.zabek@izoo.krakow.pl

1 National Research Institute of Animal Production, Krakowska 1, 32-083 Balice, Poland

2 Centre of Applied Biotechnology and Basic Sciences, University of Rzeszow, Sokołowska 26, 36-100 Kolbuszowa, Poland

\section{Introduction}

Aging encompasses a range of biological processes modified by different factors of environmental, genetic, and epigenetic nature (Bell et al. 2012). Studies concerning aging may be of interest in farm animal species. The possibility of determination of the biological age of farm animals can be important in terms of longevity, health, and extended age of reproduction (González-Recio 2011). A number of biochemical and genetic traits were involved in studying age-related processes of mammals. In addition, epigenetic marks including altered methylation profiles in conjunction with expression patterns have been widely described in the concern of cell senescence and aging in humans (Bell et al. 2012; Johansson et al. 2013; Day et al. 2013; Hannum et al. 2013). Methylation of DNA is a process catalyzed by methyltransferases and primarily affects $\mathrm{CpG}$ sites of mammalian genomes. This chemical modification has been widely mentioned in the concern of reduced activity of genes and silencing of foreign DNA (Hoelzer et al. 2008). It was recently shown that methylation patterns established at the initial stages of embryo development become deregulated with age during ontogenesis. These findings led to describing a new phenomenon called "age-associated epigenetic drift" (Johansson et al. 2013). Age-related methylation changes have been found to be important epigenetic traits for aging-related phenotypes (Bell et al. 2012). As an example, in the blood of humans, a number of age differential methylated regions (aDMRs) have been described to be associated with diseases of old age, including auto-immunity (Quintero-Ronderos and Montoya-Ortiz 2012). In this study, we assessed the impact of aging on the rate of methylation alterations of the RNASEL locus in the equine white blood cells. RNASEL belongs to the genes of the interferon signaling pathway. RNASEL encodes ribonuclease $\mathrm{L}$, which, like other RNAses, is an important mediator for the activity of cytokines 
induced by the presence of viral RNA. Thereby, induced interferons activate $2^{\prime}, 5^{\prime}$-oligoisoadenylate synthetase, which, in turn, induces ribonuclease L, destroying all RNAs within the cell, including viral particles (Squire et al. 1994). It was found that the enzymatic activity of RNASEL increases in the early stages of life, reaching a maximum level in middle-aged adult animals, thereafter decreasing considerably with age (Pfeifer et al. 1993). RNase-L was found to mediate processes blocking cell proliferation and to suppress tumor progression in cancer. Because of this, its role was tested in cell senescence and longevity (Andersen et al. 2007). We have investigated age-related methylation changes of the RNASEL locus in blood leukocyte samples of Anglo-Arabian and Hucul horses. Both breeds substantially differ in conformation traits, types of utility, nutrition requirements, and healthiness. Different environmental determinants during the formation of AngloArabians and Huculs might have led to the fixation of breedspecific epigenetic marks which we have also tried to identify on the DNA methylation level. Our aim was also to show the importance of genetic polymorphisms affecting the methylation state found in $\mathrm{CpG}$ islands.

\section{Materials and methods}

\section{Samples}

The study was done on two breeds of horses, Huculs and Anglo-Arabians. The DNA of white blood cells obtained from healthy horses was prepared and bisulfite converted using commercial kits. Two separate sets of samples were included in the range of bisulfite analysis.

\section{Sample set A}

First, blood samples derived from single individuals of both horse breeds were the subject of a cloned BSPCR sequencing approach. These included two blood samples of one AngloArabian mare and one Hucul stallion. The mentioned blood samples were repeatedly collected at different ages of both individuals in order to resolve a couple of questionable parentage cases. Namely, the source material included blood samples of the Anglo-Arabian (AA) mare collected at 13 and 21 years of age and blood samples of the Hucul (HC) stallion were collected at age 21 months and 13 years. These four samples were used to pinpoint potential age-related differences unbiased by individual specificity of methylation patterns in the RNASEL promoter region.

\section{Sample set $B$}

The second set included 27 blood samples of AA horses (13 juvenile horses and 14 individuals aged between 16 and
21 years) and 23 blood samples of the $\mathrm{HC}$ breed (11 juvenile horses and 12 horses aged between 10 and 21 years). All of these samples were subject to the direct BSPCR sequencing approach in order to determine the methylation state (using an indirect method) of three $\mathrm{CpG}$ islands in the RNASEL locus and to refer to the results obtained using sample set $\mathrm{A}$.

\section{BSPCR primer design and bisulfite amplification}

CpG islands in the RNASEL locus were determined using recommendations implemented in Cpgplot software (Larsen et al. 1992). The predicted promoter regions of RNASEL were determined using MatInspector software (Cartharius et al. 2005). Bisulfite-PCR primers were designed in the regions free of CG sites using Methyl Primer Express ${ }^{\circledR}$ Software v1.0 (Life Technologies, Poland) (Table S1). Bisulfite DNA amplification (BSPCR) was performed with the use of HotStarTaq DNA Polymerase (Qiagen) and the two-step PCR protocol. The BSPCR reaction mixture contained: $10 \mathrm{ng}$ template, $1 \times \mathrm{PCR}$ buffer [Tris- $\mathrm{HCl}, \mathrm{KCl},\left(\mathrm{NH}_{4}\right)_{2} \mathrm{SO}_{4}$, $\mathrm{pH}$ 8.7], $2 \mathrm{mM} \mathrm{MgCl}_{2}, 0.2 \mathrm{mM}$ dNTP (Applied Biosystems, CA, USA), $0.125 \mu \mathrm{M}$ primers, 1 U HotStar Taq polymerase [5 $\mathrm{U} / \mu \mathrm{L}]$ (Qiagen, Poland) and an addition of Milli-Q water to a final volume of $20 \mu \mathrm{L}$. The BSPCR reaction conditions were as follows: initial denaturation at $95^{\circ} \mathrm{C}$ for $15 \mathrm{~min}, 5$ cycles of denaturation at $97^{\circ} \mathrm{C}$ for $5 \mathrm{~s}$, annealing for $2 \mathrm{~min}$ (specified in Table S1), elongation at $72{ }^{\circ} \mathrm{C}$ for $45 \mathrm{~s}, 35$ cycles of denaturation at $97{ }^{\circ} \mathrm{C}$ for $5 \mathrm{~s}$, annealing for 2 min (specified in Table S1), elongation at $72{ }^{\circ} \mathrm{C}$ for $45 \mathrm{~s}$, and final elongation at $72{ }^{\circ} \mathrm{C}$ for $7 \mathrm{~min}$.

\section{Direct BSPCR sequencing}

BSPCR products of all individuals were sequenced using the BigDye ${ }^{\circledR}$ Terminator v3.1 Cycle Sequencing Kit (Life Technologies). The determined $\mathrm{CpG}$ islands were simultaneously searched for polymorphisms through sequencing of PCR products of unconverted DNA samples (Table S1). Sequencing reads of particular SNP variants were checked for putative amino acid changes of encoded protein using BlastX software (NCBI).

\section{Cloned BSPCR sequencing}

Amplified fragments containing mixed methylated $\mathrm{CpG}$ sites were cloned using the TOPO TA Cloning Kit (Life Technologies, Invitrogen) and subjected to cycle sequencing with universal primers. The cloning procedure was done only for sample set A. Sequencing included 16 clones of 13 years old and 20 clones of 21 years old samples of the AA mare, and 19 clones of 21 months old and 18 clones of 13 years old samples of the HC stallion. 
Methods of methylation assessment using direct BSPCR or clone sequencing data and applied statistics

After the exclusion of DNA polymorphic sites, two types of data were investigated:

- Presence or absence of methylated cytosines in single CpG positions (simple pattern of methylation)

- Percentage of methylation (PM) of partially methylated cytosines in $\mathrm{CpG}$ sites

In the first case, the methylation status was assessed using direct BSPCR sequencing reads. In the second case, the percentage of methylation (PM) was determined based on cytosine counts at particular $\mathrm{CpG}$ positions using the sequencing data of cloned BSPCR products. The methylation level (PM values) was assessed and illustrated using BISMA software (Rohde et al. 2010). The variance of PM values were calculated to show the magnitude of methylation differences between samples which vary with age and breed (sample set A). In order to calculate the relative methylation percentage of partially methylated $\mathrm{CpG}$ sites in the 50 equine blood samples (sample set B), an indirect method proposed by Leakey et al. (2008) was applied (PM values in Table S2). A linear regression model was applied to assess the methylation differences at "fuzzy" methylated CpG sites (SAS package). Supporting Duncan's tests were performed at the 0.05 level of significance.

\section{Results}

\section{Methylation state of $\mathrm{CpG}$ islands}

Three predicted CpG islands (CGIs) of the RNASEL locus were the target of the study concerning methylation status and the effect of genetic polymorphisms in particular $\mathrm{CpG}$ sites. CGI1 was placed on the $5^{\prime}$ site covering the promoter region and the other two islands were placed inside the gene. CGI3 covered a part of exon 2 (Fig. 1). Bisulfite sequencing of
50 blood leukocyte samples revealed hypomethylated state of $18 \mathrm{CpG}$ sites of CGI1 in opposite to hypermethylation detected in the $\mathrm{CpG}$ sites of islands located inside the gene (Table S3).

\section{DNA polymorphism affecting methylation state in the CG context}

Alignment between the sequence of converted and unconverted DNA revealed three SNP-CpG sites in CGI1 and single sites in CGI2 and CGI3 in both horse breeds. The occurrence of $\mathrm{T}$ and $\mathrm{G}$ variants of the CGI1 region changed the methylation status of $\mathrm{CpG} 9$ and $\mathrm{CpG} 21 \mathrm{~m}$ respectively. In turn, the presence of allele $\mathrm{A}$ disrupted the methylation of single SNP-CpGs located in CGI2 and CGI3 (Table 1, Appendix S1). Pairwise comparison of epigenotype frequencies between SNP-CpG5 and CpG5 sites found in the CGI2 and CGI3 regions in both breeds revealed linkage disequilibrium between allele $\mathrm{G}$ and methylated cytosine within $\mathrm{CpG}$ sites (Table 1). In turn, the presence of allele A lead to the loss of methylated alleles at the mentioned $\mathrm{CpG}$ sites (example given in Appendix S1). The described $\mathrm{CpG}$ sites showed that monoallelic methylation occurred in both horse breeds with different frequencies (Table 1). The BlastX search revealed putative amino acid changes due to polymorphism at the SNP-CpG5 of the CGI3 region. The presence of allele $A$ resulted in His to Arg non-conservative amino acid (aa) change at the 34 aa position of sequence no. ABN49949 (Table 1). Polymorphic $\mathrm{CpG}$ sites were excluded from investigations of age- and breed-related methylation changes.

\section{Methylation assessment in the concern of age and breed using clones and direct BSPCR sequencing data}

Mixed methylation at the first eight $\mathrm{CpG}$ sites of CGI1 formed the basis for the calculation of methylation differences in the concern of breed and age. Comparison of PM values calculated from clone sequencing data and those based on the method of Leakey et al. (2008) showed similar

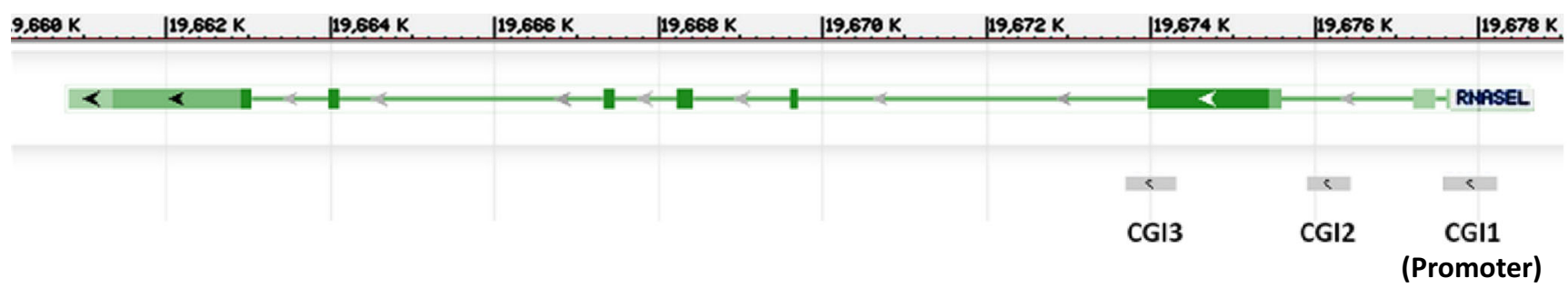

Fig. 1 The layout of CpG islands (grayed) in the RNASEL locus based on the sequence alignment scheme (BLASTn). Exons are depicted as green vertical bars and the arrows indicate sequence orientation (gene annotated from the reverse strand of the genomic sequence) 
Table 1 Epigenotype frequencies of $\mathrm{CpG}$ sites influenced by genetic polymorphism

\begin{tabular}{|c|c|c|c|c|c|c|}
\hline Site & NCBI accession no. & Genomic location $^{\mathrm{a}}$ & CGI & Breed & Epigenotype & Frequencies $^{\mathrm{b}}$ \\
\hline \multirow[t]{2}{*}{ SNP-CpG9 } & \multirow[t]{2}{*}{ ss\#944501432 } & \multirow[t]{2}{*}{19677890} & \multirow[t]{2}{*}{ CGI1 } & AA & \multirow[t]{2}{*}{$\mathrm{CC} / \mathrm{CT} / \mathrm{TT}$} & $0 / 0,069 / 0,931$ \\
\hline & & & & $\mathrm{HC}$ & & $0 / 0,167 / 0,833$ \\
\hline \multirow[t]{2}{*}{ SNP-CpG21 } & \multirow[t]{2}{*}{ ss\#944501434 } & \multirow[t]{2}{*}{19677716} & \multirow[t]{2}{*}{ CGI1 } & AA & \multirow[t]{2}{*}{$\mathrm{CC} / \mathrm{CG} / \mathrm{GG}$} & $0,034 / 0,379 / 0,586$ \\
\hline & & & & $\mathrm{HC}$ & & $0,033 / 0,2 / 0,767$ \\
\hline \multirow[t]{2}{*}{ CpG5 } & \multirow[t]{2}{*}{-} & \multirow[t]{2}{*}{19676068} & \multirow[t]{2}{*}{ CGI2 } & $\mathrm{AA}$ & \multirow[t]{2}{*}{$\mathrm{CC} / \mathrm{CT} / \mathrm{TT}$} & $\underline{0,5 / 0,346 / 0,154^{\mathrm{c}}}$ \\
\hline & & & & $\mathrm{HC}$ & & $\overline{0,367 / 0,5 / 0,133}{ }^{d}$ \\
\hline \multirow[t]{2}{*}{ SNP-CpG5 } & \multirow[t]{2}{*}{ ss\#944501428 } & \multirow[t]{2}{*}{19676069} & \multirow[t]{2}{*}{ CGI2 } & AA & \multirow[t]{2}{*}{ GG/AG/AA } & $\underline{0,5 / 0,346 / 0,154}$ \\
\hline & & & & $\mathrm{HC}$ & & $\overline{0,367 / 0,5 / 0,133}$ \\
\hline \multirow[t]{2}{*}{ CpG5 } & \multirow[t]{2}{*}{-} & \multirow[t]{2}{*}{19674196} & \multirow[t]{2}{*}{ CGI3 } & AA & \multirow[t]{2}{*}{$\mathrm{CC} / \mathrm{CT} / \mathrm{TT}$} & $\underline{0,458 / 0,25 / 0,292}$ \\
\hline & & & & $\mathrm{HC}$ & & $0,208 / 0,583 / 0,208$ \\
\hline \multirow[t]{2}{*}{ SNP-CpG5 } & \multirow[t]{2}{*}{ ss\#944501446 ${ }^{\mathrm{e}}$} & \multirow[t]{2}{*}{19674197} & \multirow[t]{2}{*}{ CGI3 } & AA & \multirow[t]{2}{*}{ GG/AG/AA } & $0,458 / 0,25 / 0,292$ \\
\hline & & & & $\mathrm{HC}$ & & $\overline{0,208 / 0,583 / 0,208}$ \\
\hline
\end{tabular}

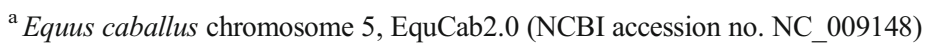

${ }^{\mathrm{b}}$ Epigenotype frequencies are ordered as homozygous for epiallele 1/heterozygous/homozygous for epiallele 2 (determined using BSPCR sequencing reads of 27 samples of AA and 23 samples of HC horses)

${ }^{\mathrm{c}}$ Similar epigenotype frequencies between CpG5 and SNP-CpG5 found in the CGI2 and CGI3 regions among AA horses are underlined

${ }^{\mathrm{d}}$ Similar epigenotype frequencies between CpG5 and SNP-CpG5 found in the CGI2 and CGI3 regions among HC horses are in bold

${ }^{\mathrm{e}}$ Functional polymorphism resulting in 34 aa His to Arg substitution

results (Appendix S2). In silico search for transcription factor binding sites (TFs) covering sequences of partially methylated CpGs of the RNASEL promoter (Matinspector software) did not reveal any sites of TFs expressed in the blood cells.

\section{Methylation assessment using sample set A}

The sequencing results of cloned BSPCR products of leukocyte samples of different ages and breeds revealed similar averaged PM values across all CpG sites of the RNASEL promoter (Table S4). Concerning particular $\mathrm{CpG}$ sites, the greatest PM differences were observed for blood samples of male Hucul horses. The substantial age-related methylation decrease for $\mathrm{CpG} 7$ and significant methylation increase for CpG8 were detected in the Hucul blood samples (greatest values of variance) (Table S4). PM differences at both mentioned $\mathrm{CpG}$ sites between blood samples of different ages of the AA mare were proportional; however, they were substantially smaller (lower values of variance) (Table S4). In turn, large PM differences were detected in $\mathrm{CpG} 7$ between the blood samples of the 13-year-old male Hucul and the 13year-old female AA horse (the greatest value of variance) (Table S5).

\section{Methylation assessment using sample set $B$}

Application of methylation assessment using the method of Leakey et al. (2008) did not reveal any significant differences in the concern of breed (Table 2). Implementation of the linear regression model for the data set comprising BSPCR sequencing reads of 50 blood samples confirmed the significant agerelated changes at $\mathrm{CpG} 8$ and, additionally, revealed significant values for $\mathrm{CpG} 4$ and $\mathrm{CpG} 5$ (Table 2). The average methylation levels for $\mathrm{CpG} 4, \mathrm{CpG} 5$, and $\mathrm{CpG} 8$ were higher in a group of horses older than 1 year of age than those assessed for juvenile individuals in both breeds (Table 3).

\section{Discussion}

\section{Description of methylation patterns across the RNASEL locus}

Ongoing changes during ontogenesis affect the number of particular cell types, leading to modifications in tissue composition. One of the epigenetic features of these changes are alterations in DNA methylation patterns throughout the lifespan, which can be cell- and tissue-specific (Johansson et al. 2013; Jaffe and Irizarry 2014). This study describes the methylation patterns of the RNASEL locus in the equine blood leukocytes. Hypomethylation of the majority of $\mathrm{CpG}$ sites covering the RNASEL promoter region coincides with the hypermethylated state of $\mathrm{CpG}$ islands inside the gene. It was found that, in humans, the observed state of methylation patterns was a feature of about $70 \%$ of genes actively transcribed throughout the lifespan (Day et al. 2013). In turn, a range of studies on human epigenomes allowed also to detect a number 
Table 2 The effect of age and breed on eight $\mathrm{CpG}$ sites with the addition of distribution statistics

\begin{tabular}{llllllllll}
\hline \multicolumn{1}{c}{ GLM significance/distribution statistics } \\
\cline { 2 - 9 } & CpG1 & CpG2 & CpG3 & CpG4 & CpG5 & CpG6 & CpG7 & CpG8 & CpG average \\
\hline Breed & $\mathrm{ns}$ & $\mathrm{ns}$ & $\mathrm{ns}$ & $\mathrm{ns}$ & $\mathrm{ns}$ & $\mathrm{ns}$ & $\mathrm{ns}$ & $\mathrm{ns}$ & $\mathrm{ns}$ \\
Age &. & $\mathrm{ns}$ & $\mathrm{ns}$ & $* *$ & $* * *$ & $\mathrm{~ns}$ & $\mathrm{~ns}$ & $* * *$ & $* * *$ \\
$\chi$ & 95.2 & 88.8 & 86.2 & 82.9 & 49.5 & 27.0 & 57.9 & 68.9 & 65.9 \\
Median & 94.6 & 89.5 & 87.9 & 83.5 & 50.9 & 28.9 & 58.3 & 71.6 & 66.1 \\
SD & 3.9 & 6.5 & 9.3 & 9.1 & 12.6 & 13.2 & 15.8 & 15.9 & 7.5 \\
\hline
\end{tabular}

$* * * p<0.001 ; * * p<0.01 ; * p<0.05 ; . p<0.1 ;$ ns' non-significant of $\mathrm{CpG}$ islands and single $\mathrm{CpG}$ sites with variable methylation levels during the lifespan (Bell et al. 2012; Johansson et al. 2013; Day et al. 2013; Hannum et al. 2013). In this study, a couple of "fuzzy" methylated CpG sites were observed in the RNASEL promoter, which were used to investigate some breed- and age-related changes.

\section{Polymorphic sites affecting methylation state in the CG context}

Differences in methylation status affected by DNA polymorphisms were the source of interindividual epigenetic variation detected in both breeds. The presence of heterozygous genotypes in SNP-CpG sites overlapped with $\mathrm{CpG}$ monoallelic methylation, which occurred with different frequencies in particular breeds. Polymorphisms of SNP-CpG sites located in the promoter area could contribute to the binding effectiveness of methylation-dependent transcription factors. Such an impact of methylation on significant SNP-CpG sites has been described by Hellman and Chess (2010) and Shoemaker et al. (2010). In turn, one of the identified intragenic SNPCpGs represents functional polymorphism, introducing nonconservative amino acid substitution in the region of the protein domain which would impair the enzymatic activity of $R N A S E L$. It was found that impairment of RNASEL in old age results in increased susceptibility to viral infections in model animals (Pfeifer et al. 1993). Loss of methylation conditioned by the occurrence of allele A at this SNP-CpG site would, then, be a putative indicator of improper function of the enzyme.

\section{Age- and breed-related changes of methylation profiles in the RNASEL promoter}

At first, partially methylated $\mathrm{CpG}$ sites of the RNASEL promoter were investigated using cloned BSPCR sequencing data. $\mathrm{CpG}$ hypermethylation was detected when comparing blood samples collected at different ages of the investigated individuals except for $\mathrm{CpG}$, where increased hypomethylation was observed. Thus, the obtained results confirmed the variation of methylation levels between $\mathrm{CpG}$ sites, even in short DNA stretches. The site-specific phenomenon of DNA methylation in the promoter area may be related to the dynamic nature of transcriptional machinery involving different chromatin states which determine the availability of particular transcription factor binding sites (Marchal and Miotto 2015). It should be noted that white blood cells include a number of leukocyte subtypes which can reveal different states of methylation in particular genomic areas (Talens et al. 2010). Because of this, it is possible that observed differences of methylation between blood samples collected from the AA mare and $\mathrm{HC}$ stallion at different ages might coincide with changes in the cellular fraction of blood leukocytes during aging. In addition, observed age-related methylation could overlap with breed- or sex-specific effects (when comparing CpG7 methylation profiles between blood samples of the HC
Table 3 Mean percentage of methylation (PM) values of three $\mathrm{CpG}$ sites showing significant age-related differences of methylation profiles

\begin{tabular}{|c|c|c|c|c|c|c|}
\hline \multirow[t]{2}{*}{ Site } & \multicolumn{2}{|l|}{$\mathrm{AA}$} & \multicolumn{2}{|l|}{$\mathrm{HC}$} & \multicolumn{2}{|c|}{ Both breeds } \\
\hline & Juvenile & Adult & Juvenile & Adult & Juvenile & Adult \\
\hline CpG4 & $70,78974^{\mathrm{a}}$ & 76,05388 & 67,98497 & 77,79421 & 69,50422 & 76,85711 \\
\hline CpG5 & 77,18779 & 87,01256 & 80,2084 & 87,02527 & 78,57224 & 87,01843 \\
\hline CpG8 & 80,0514 & 85,22565 & 79,8284 & 83,69635 & 79,94919 & 84,51982 \\
\hline
\end{tabular}

${ }^{\text {a }}$ PM was calculated using the method of Leakey et al. (2008) and averaged across samples of juvenile and adult horses within each breed separately and regardless of breed. Increased age-related hypermethylation is observed 
male and AA female of similar age). For example, detailed evidence for sex and ethnic specificity of age-related methylation profiles has been given using microarrays methylome data of white blood cells of the healthy human population (Hannum et al. 2013). To assess the magnitude of methylation changes at partially methylated $\mathrm{CpG}$ sites in the RNASEL promoter area, we also applied an indirect measure of PM values (Leakey et al. 2008) across a set of 50 blood leukocyte samples from both horse breeds. A general tendency observed in the studied equine leukocyte samples was consistent with the age-related methylation increase of particular CpGs located in promoter regions (Johansson et al. 2013). It is interesting that the use of the indirect method of methylation assessment did not reveal any significant breed-specific effects across eight $\mathrm{CpG}$ sites of the RNASEL promoter. The sole source of differences between both horse breeds were genetic polymorphisms affecting the methylation state of $\mathrm{CpG}$ sites. The only result being common to both methods of methylation assessment in this study (cloning procedure versus the indirect measure of PM values) is the occurrence of increased methylation during age. Hypermethylation of CpG8 in the RNASEL promoter could, then, be treated as a potential age-related epigenetic feature of equine white blood cells. A further question is if the detected "fuzzy" methylated CpG sites in the promoter area are of functional importance for $R N A S E L$ activity.

The conducted research revealed the presence of locusspecific methylation changes which have potential value for studies on aging of the blood system of the horse. The inclusion of genetic and epigenetic variation into association and functional studies may provide novel findings about RNASEL activity during viral infections.

Acknowledgments Author's project of the National Science Centre in Poland, project no. N N311 539340.

Open Access This article is distributed under the terms of the Creative Commons Attribution 4.0 International License (http:// creativecommons.org/licenses/by/4.0/), which permits unrestricted use, distribution, and reproduction in any medium, provided you give appropriate credit to the original author(s) and the source, provide a link to the Creative Commons license, and indicate if changes were made.

\section{References}

Andersen JB, Li XL, Judge CS, Zhou A, Jha BK, Shelby S, Zhou L, Silverman RH, Hassel BA (2007) Role of 2-5A-dependent RNase-L in senescence and longevity. Oncogene 26(21):3081-3088

Bell JT, Tsai PC, Yang TP, Pidsley R, Nisbet J, Glass D, Mangino M, Zhai G, Zhang F, Valdes A, Shin SY, Dempster EL, Murray RM, Grundberg E, Hedman AK, Nica A, Small KS; MuTHER
Consortium, Dermitzakis ET, McCarthy MI, Mill J, Spector TD, Deloukas P (2012) Epigenome-wide scans identify differentially methylated regions for age and age-related phenotypes in a healthy ageing population. PLoS Genet 8, e1002629

Cartharius K, Frech K, Grote K, Klocke B, Haltmeier M, Klingenhoff A, Frisch M, Bayerlein M, Werner T (2005) MatInspector and beyond: promoter analysis based on transcription factor binding sites. Bioinformatics 21:2933-2942

Day K, Waite LL, Thalacker-Mercer A, West A, Bamman MM, Brooks JD, Myers RM, Absher D (2013) Differential DNA methylation with age displays both common and dynamic features across human tissues that are influenced by CpG landscape. Genome Biol 14(9): R102

González-Recio O (2011) Epigenetics: a new challenge in the postgenomic era of livestock. Front Genet 2:106

Hannum G, Guinney J, Zhao L, Zhang L, Hughes G, Sadda S, Klotzle B, Bibikova M, Fan JB, Gao Y, Deconde R, Chen M, Rajapakse I, Friend S, Ideker T, Zhang K (2013) Genome-wide methylation profiles reveal quantitative views of human aging rates. Mol Cell 49: 359-367

Hellman A, Chess A (2010) Extensive sequence-influenced DNA methylation polymorphism in the human genome. Epigenetics Chromatin 3:11

Hoelzer K, Shackelton LA, Parrish CR (2008) Presence and role of cytosine methylation in DNA viruses of animals. Nucleic Acids Res $36: 2825-2837$

Jaffe AE, Irizarry RA (2014) Accounting for cellular heterogeneity is critical in epigenome-wide association studies. Genome Biol 15(2):R31

Johansson Å, Enroth S, Gyllensten U (2013) Continuous aging of the human DNA methylome throughout the human lifespan. PLoS One 8, e67378

Larsen F, Gundersen G, Lopez R, Prydz H (1992) CpG islands as gene markers in the human genome. Genomics 13:1095-1107

Leakey TI, Zielinski J, Siegfried RN, Siegel ER, Fan CY, Cooney CA (2008) A simple algorithm for quantifying DNA methylation levels on multiple independent $\mathrm{CpG}$ sites in bisulfite genomic sequencing electropherograms. Nucleic Acids Res 36, e64

Marchal C, Miotto B (2015) Emerging concept in DNA methylation: role of transcription factors in shaping DNA methylation patterns. J Cell Physiol 230(4):743-751

Pfeifer K, Ushijima H, Lorenz B, Müller WE, Schröder HC (1993) Evidence for age-dependent impairment of antiviral 2',5'oligoadenylate synthetase/ribonuclease L-system in tissues of rat. Mech Ageing Dev 67:101-114

Quintero-Ronderos P, Montoya-Ortiz G (2012) Epigenetics and autoimmune diseases. Autoimmune Dis 2012:593720

Rohde C, Zhang Y, Reinhardt R, Jeltsch A (2010) BISMA—fast and accurate bisulfite sequencing data analysis of individual clones from unique and repetitive sequences. BMC Bioinformatics 11:230

Shoemaker R, Deng J, Wang W, Zhang K (2010) Allele-specific methylation is prevalent and is contributed by CpG-SNPs in the human genome. Genome Res 20:883-889

Squire J, Zhou A, Hassel BA, Nie H, Silverman RH (1994) Localization of the interferon-induced, 2-5A-dependent RNase gene (RNS4) to human chromosome 1q25. Genomics 19:174-175

Talens RP, Boomsma DI, Tobi EW, Kremer D, Jukema JW, Willemsen G, Putter H, Slagboom PE, Heijmans BT (2010) Variation, patterns, and temporal stability of DNA methylation: considerations for epigenetic epidemiology. FASEB J 24:3135-3144 